Portland State University

PDXScholar

$5-25-1973$

\title{
Effects of speaker-sex-difference on listeners' perception of vocal roughness in normal vowel productions
}

Patsy J. Phillips

Portland State University

Follow this and additional works at: https://pdxscholar.library.pdx.edu/open_access_etds

Part of the Gender, Race, Sexuality, and Ethnicity in Communication Commons, and the Speech Pathology and Audiology Commons

Let us know how access to this document benefits you.

\section{Recommended Citation}

Phillips, Patsy J., "Effects of speaker-sex-difference on listeners' perception of vocal roughness in normal vowel productions" (1973). Dissertations and Theses. Paper 1731.

https://doi.org/10.15760/etd.1730

This Thesis is brought to you for free and open access. It has been accepted for inclusion in Dissertations and Theses by an authorized administrator of PDXScholar. Please contact us if we can make this document more accessible: pdxscholar@pdx.edu. 
AN ABSTRACT OF PrE TIIESIS OF Patsy J. Philitips for the Master of Science in Speech Pathology presented May 25, 1973.

Title: Effects of Speaker-Sex-Difference on Lisianexs Perception of Vocal Roughress in Normal Vowel Productions.

APPROVED BY MEMBERS OH THE THESIS CORMITTEE:

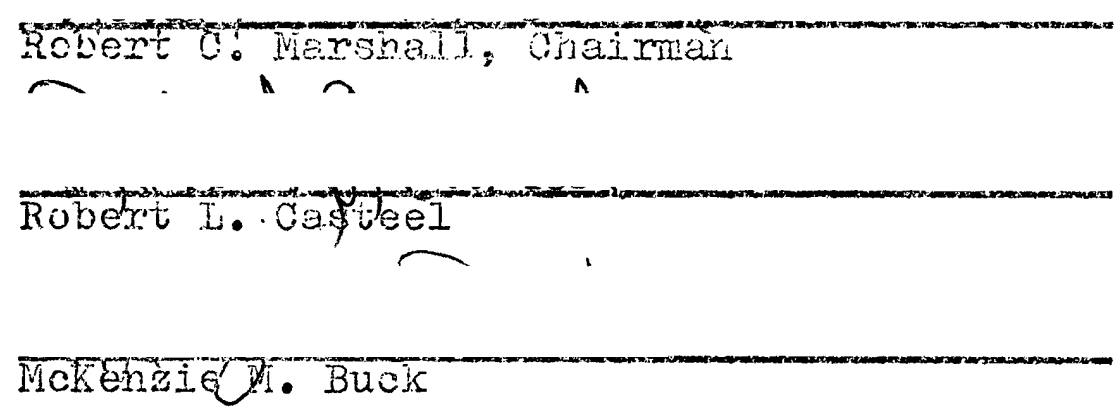

The purpose of this study was to investigate the effects of speakermsex-aifference on Iisteners' perception of vocal roughiness in the vowel [æ] produced by normal male and fernale speakers. In a previous investigation by Wendahl (1963) it was found that when Iistening to two synthesized vowels, of equal. aperiodicity, judges tended to rate the lower pitched rowel as being moxe rocally rough. If this is true for listeners yerception of human vowel productions as well then it mifint be advantegeous for voice clinicians, 
when making vocal roughness assessments, to regard male and female speakers as two separate populations in view of the inherent pitch differences between the sexes.

In this current investigation, pairs of vowels produced by normal adult male and female speakers were presented to 10 speech pathologists ( 5 males and 5 females). Each vowel pair contained one male and one female production of the vowel [a] which had been assigned equal roughness ratings in a previous judging task. The 50 vowel pairs contained 10 pairs of vowels at each of five roughness rating levels. The 10 judges were required to listen to each of the 50 pairs and to make a forcedchoice zeleation of the most rocally rough production within each pair.

The findings in this study revealed that for the 50 vowel pairs the judges selected the vowels produced by males as being more vocally rough a significantly greater proportion of the time. With respect to the five roughness rating levels, judges chose the male produced vowels as being rougher a significantly greatex proportion of the time at rating levels one, three and five but illustrated no significant preference between the sexes at rating levels two and four. Further analysis revealed that the five male judges selected the vowels produced by males as being the rougher a significantly greater proportion of the time for all. 50 pairs at each of the five roughness ratirg 
levels. The five female judges, on the other hand, illustrated no significant preferences between the sexes for the 50 vowel pairs. They did show a significant preference for the males at rating level one, a significant preference for the females at rating level two but no sigmificant at rating levels three, four and five. In addition, male judges illustrated substantially greater inter-judge agreement and intra-judge reliability for this judging task than did the female judges. 
EFFECRS OF SPTAYTR-SEX-DIFFTRANCE ON ITSTENERS

PERCIPTION ON VOCAI ROUJGENESS IN

NORMEL VOWEL PRODUCUIONS

by
PATSY J. PHIIIIIPS

A thesis submitted in partjal fulfillment of the requirements for the degree of

MASTER OF SCIENCE IN SPEECH:

ENPHASIS SPEECH PATHOIOGY AND AUDIOLOGY

Portland State Uriversity

1973 
TO THE OFFICE OF GRADUAPE SPUDIES AND RESEARCH:

The members of the committee approve the thesis of Patsy J. Phillips presented May 25, 1973.

$$
\text { Robert C. MarahajI, Chairman }
$$

Robedt I. Cagfe't

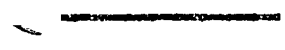

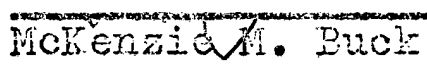

APPROVEI:

Robert W. VogeIspts, Head, Opepartment of Speech

Darid 1. Clark, Dean of Graduate Studies and Research

May 25, 1973 
ACKNOWLEDGNENSS

The author wishes to express her gratitude to Dr. Robert C. Marshall, director of this study, for his invaluable guidance, support and patience throughout the planning and completion of the investigation. Appreciation is also expressed to the members of the thesis committee, Dr. McKenzi.e Buck and Dr. Robert I. Casteel, for their constant encouragement, and cooperative efforts to expedite the completion of this study.

Additional acknowledgment is made to Dr. Jack $R$. Hegrenes, Child Development Rehabilitation Center, University of Oregon Medical School, for his invaluable assistance in the statistical analysis of the data. Thanks are also extended to the thirteen people who served as judges and to the 150 individuals who served as subjects. The author also wishes to express her gratitude to her husband $\mathrm{Bob}$ and trree children for their untiring patience, encouragement and cooperation throughout this period of graduate study. 
TABLE OF CONTENTS

PAGE

ACKNOWLEDGNENTS

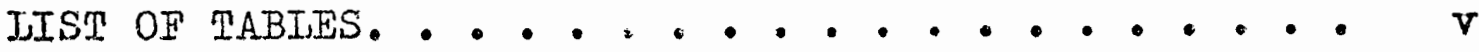

CHAPTER

I INTRODUCIION, . • . . . . . . . . 1

Statement of the Problem. ...... 3

II REVIEW OF TIE IIITERATURE. • . • • • . 5

III METHODS AND PROCEDURES. . . . . . . 14

Research Question ........ 14

Iistening Tape 1....... 16

Iistenjing Tape 2. . . . . . 17

IV RESULTS AND DISCUSSION. . . . . . . . 21

Results........... 21

Discussion. ....... 35

$\mathrm{V}$ SUMMARI AND CONCLUSIONS ....... 40

Summary . . . . . . . . 40

Conclusions .......... 42

BIBIIOGRAPHY. . . . . . . . . . . . 44 APPENDIX

A JUDGES. .............. 46

B JTR-2 PATR ERTSENTATION ORDER. . . . . . 48 
LIST OF TABIJES

IABLE

PAGE

I Three Judges Roughness Ratings on a Five Point Scale for sach Male and Female Vowel Production . . . . . . . . . . 22823

II Degree of kgreement by mhree Judges on Roughness Ratings of Seventy-Five Male and Seventy-Five Female Productions of the Vowel [x] . . . . . . . . . 24

III Ten Judges: Selections by Sex of the Most Vocally Rough Vowels of Fifty Vowel Pairs. •. . . . . . . . . . . .

IV Ten Juages' Selections by Sex of the Most Vocally Rough Vowels of Ten Vowel Pairs at Each of the five Roughness Rating Ievels . . . . . . . . . . . 26

$V$ Five MaIe and Five Female Judges' Selections by Sex of the Most Focally Rough Vowel Production . . . . . . . . 27

VI Five Male and rive Female Judges' Selections by Sex of the Most Vocally Rough. Vowel Production at Each of Five Roughness Rating Levels . . . . . . . . . . . 
VII Intra-Judge Reliability . . . . . . 30

VIII Percentage of Intej--Juage Agreement for Fifty Pairs of Vowel Samples. . . . . 31

IX Percentage of Inter-Judge Agreement by Ten Judges at Roughness Rating Level one. . . 32

$X$ Percentage of Inter-Judge Agreement by ten Judges at Roughness Rating Level Two. . . 32

XI Percentage of Inter-Judge kgreement by Ten Judges at Roughness Rating Ievel Three. .

XII Percentage of Inter-Judge Agreement by tien Judges ac Roughness Ratirg Jevel Four . .

XIJ Percentage of Inter induse Aonsecment by men Judges at Roughness Rating LeveI Five . . • 
CHAPTSR I

\section{INTRODUCTION}

Practicing clinicians readily recognize the clinical significance of making perceptual judgementss of vocal quality aberration and fluctuation. Such judgements, when accurately and reliably made, may be employed to reflect the patient's voice improvement (or lack of such) with treatment and to alert the medical specialists of the possibility of existing or continuing laryngeal pathology. Most of the literature perteining to voice disorders indicates that rocal quality is the principal parameter of concerm to the voice clinician. Although clinicians utilize different terms to describe an aberrant vocal quality (hoarseness, harshness, raspiness, huskiness, etc.) these quality disturbances can be converiently grouped under the general term of vocal roughness (Third Regional Workshop on the Rehabilitation Codes and Ccmminicative Disorder 1967). This term is useful also in that it can be used to describe a quality inherent in the normal voice (but to a lesser degree) as well as in the pathological voice (Sansone and Emanuel, 1970; Iively and Emanuel, 1970; Whitekead, 1970; Hanson, 1970).

The voice clinician will have in his caseload both 
male and female clients who manifest wough vosal quality. It is interesting, however, that when speaking of vocal quality aberrations most clinicians tend to regard their male and female patients as a single population. Ihis tendency is not observed in the assessment and treatment of patients of both sexes with respect to disturbances in other vocal parameters. It is generally accepted that the mean pitch and loudness levels of the adult male voice ins significantly lower ard louder than that of the Iemale voice (Boone, 1971; Brodnitz, 1968; Tairoanks, 1960; Fisher, 1966; Green, 1966; Murphy, 1964). For this reason the two sexes are generally viewed as two disinct populations with regard to these parameters.

While the pitch and loudness levels of the male and female voices are distinctly different one must realize that these parameters are intinately related to the percep. tion of vocal quality. phis suggests perhaps that males and females might be regarded as two populations with respect to vocal quality. Support for the view that sex. difference may play an important part in the assessment of aberrant rocal quality was initially offered by wendahl (1963) who used a laryngeal analog to generate complex acoustic stimuli which varied randomy around median frequencies of $100 \mathrm{~Hz}$ and $200 \mathrm{~Hz}$. He found that very slight cycle-to-cycle frequency valiations (as little as plus or minus $1 \mathrm{~Hz}$ ) were pereeived as rough and that the 
same Irequency variations around a median frequency of $100 \mathrm{~Hz}$ received higher (more rough) roughness ratings than the same frequency variations around a median frequency of $200 \mathrm{~Hz}$. Wendahl hypothesized that if the vowel productions of male and female voices of equal aperiodicity were rated for rocal roughness, the male voice would be rated as the rougher of the two on the basis of its lower pitch level. Some limited experimentaI support for this hypothesis has been offered by Sansore and Emanuel (1970) and Lively and Pmanuel (1970) who found that listeners vocal roughness ratings of normal speakers vowel productions encompassed a greater range of severity for mal.e than for female sub.jects. Wendahl's oxiginol hypothesis has yet to be clinically validated, howevex.

\section{STAPEMENT OF THE PROBLEN}

With the exception of the studies by Sansone and Emanuel (1970) and Iively and Emanuel (1970), the literature reveals a lack of information with respect to the effects of sex difference on perceptual judgements of vocal roughness in the human voice. Information with respect to the influence of the speaker's sex upon vocal roughness assessment could be valuable to the practicing clinician who must rely on his perceptual skills to make such assessments. Accordingly the principle purpose of this study was to investigate the effects of speaker-sex- 
difference on listeners' perceptual judgements of vocal roughness on the vowel [e] produced by normal male and Iemale speakers. 


\section{CHAFPEP II}

\section{REVIEW OF THE IITERATURE}

Investigation of the Iaryngeal nechanism indicates that for the normal voice the motion of the vocal folds is relativeiy periodic (Timcke, vonLeden and Moore, 1958), whereas the vocal fold vibcatory pattern for rough voice evidences aperiodic movements (Moore and Thompscn, 1967). Ainormality has also been noted in the acoustical wave spectra of jindividuals prosenting rocal roughness. A number of studies report the exjstence of ranacm variations in the periods of successive cycles of productions ailong subjects with deviant vocal quality. Such frequency variations have been found to be highly correlated with listeners' perception of vocal roughness. For example, in an analysis of the fundamental frequency characteristics of harsh vocal quality, Bowler (1964) employed an oscillograph to examine recordings of harsh and non-harsh connected speech samples. He reported that the most striking feature in the harsh portions of connected speech samples was the presence of "frequency breaks." These frequency breaks occurrea in both upward and dowmward directions of the frequency scale and typically encompassed a range of one octave. In no instance did the segments perceived as non-harsh contain 
these frequency break characteristics. In addition, the harsh segments were found to have lower mean fundamental frequencies than the non-harsh segments. Coleman (1960) evaluated sustained vowels produced by pathologically hoarse subjects but failed to find frequency breaks as large as those reported by Bowler. He did, however, identify aperiodic cycle-to-cycle frequency variations of less than one octaye which he termed "voice breaks." These voice breaks were prominent in the waveform of the subjects' phonations, and their presence was closely associated with the degree of perceived hoarseness. In a study of laryngitic hoarseness, Shipp and Huntingtion. (1965) a7so found vojce breaks to be less frequent than those reported by Boviler. When present, however, such breaks were felt to contribute greatly to the perception of hoarseness. Also in contrast to Bowlex's (1964) findings, Shipp and Huntington noted a more restricied range of fundamental frequencies for their hoarse subjects and failed to find significant differerces between either mean or median fundamental frequencies for hoarse and normal voices. Iieberman (1963) and Michel (1964) have also suggested that the fundamental frequencies of abnormally rough speakers are within the modal range for the subject's age and sex.

Other studies of disturbances evidenced in the phonatory acoustic waves, suggest that the duration of cycle-to- 
cycle frequency variatjons also. affect perception of vocal roughness. Cooper, Peterson and Fahringer (1957) found that when period variations were eliminated from synthesized speech samples J.isteners perceived the sample to be mechanical and unnatural. This finding is consistent with Lieberman's (1967) observation that pitch perturbations (small, rapid variations in the duration of successive cycles) are apparently essertial cues to'natural speech quality. He found that in romally produced vowels the perturbation factor is small in comparison to those in rough vowels. Perturbations of less than $0.5 \mathrm{~ms}$ were typical of normally phonated isolated vowels; for mildzy anà moderately rough phonations, however, the perturbation factor generaliy exceeded that of normal phonation. Michel (1964) points out that a wave is aperiodic when there is ". . a lack of recognizable repeating wave-forms." He determined the amount of time that the phonatory acoustic wave was aperiodic in relation to the total phonation time for standardized passages of connected speech spoken with harsh, vocal fry, and normal rocal qualities. The total time of each sample was first measured by phonellographic records of the signal. Subsequentiy, the amount of aperiodicity, or that portion of the total signal which lacked recognizable re-appearing cycles was determined and a ratic computed by dividing the time of aperiodicity by total phonation time. This made it possible to specify the proportion of total phonation time 
a phonatory signal was characterized by aperiodicity. Michel concluded that normal sustained vowel phonations are aperiodic approxinately two percent of the time, while harsh phonations axe aperiodic approximately seventeen percent of the time.

Additional incornation, supporting the premise that rancom variations in the periods of successive cycles in the roice wave are associated with perception of vocal roughness, has been contributed through study of acoustic analogs of phonation. To investigate the degree of signal aperiodicity requirea for listener judgements of roughness, Wendahl (1963, 1966a, 1966b) employed an electrical laryngeal analog to generate complex acoustic stimuli which varied randomly in frequency around a median frequency. He reported that slight frequency variations, as small as plus one cycle around a median frequency of $100 \mathrm{~Hz}$, caused the signal to be perceived as rough. As the frequency variation around the median frequency increased, listeners perceived an increase in signal roughmess. In a later study, Coleman and Wendahl (1967) provided more quantitative data regarding the relationship between stimulus duration and perceived vocal roughness. They found cycle-to-cycle frequency variations, which they callea "jitter," in a synthesized complex wave were related to perceived signal roughness. They also synthesized complex acoustic stimuli which contained both aperiodic and periodic components so 
that the duration of the aperiodic segments within the total stimulus, as welI as the amount of aperiodicity around a median frequency, could be varied. As the duration of the aperiodic segment increpsed from .16 to .80 seconds in a signal of finite length, more severe roughness was perceived by the listeners. A trading relationship between the duration and the amount of aperiodicity in the signal was also revealed. In other words a stimulus containing large cycle-to-cycle frequency variations, within a short aperiodic segment, was judged less rough than a stimulus containing an aperiodic segment of longer duration and smallex speriodic excursion.

Rerentily, souna spectrographic arialyses have yielded additional information regarding the acoustic properties of vocal roughness. A number of investigations have provided data on the suprafundamental energy distribution within the wave envelope and how this energy distribution relates to perceived roughness. Isshiki, Yanagihara, and Morimoto (1966) and Yanasihara (1967a, 1967b), in studying harmonic and noise components in the spectra of sustained vowels phonated by subjects with laryngeal pathologies found that noise components were mixed with the harmonics in the formant regions for speakers evidencing slight hoarseness. This was particularly evident in the second and third formants. As the severity of hoarseness increased, the noise components tended to appear in the high frequency 
region above $3000 \mathrm{~Hz}$. Yanagihara (1967a) also observed a relationship between the degree of spectral noise abnormality and the magnitude of cycle-to-cycie variations in the shape, amplitude and periodicity of the glottal area waves as measured by ultra--high speed cinematographic analysis. To support his findings for human phonations, Yanagihara (1967b) synthesized hoarseness by mixing recorded normal vowels with band-pass filtered roise. He found that as the noise components intruded into formant ranges and as the high frequency hamonic componerts became obscured by noise, the severity of perceived hoarseness increased. More recently Sansone and Emanuel (1970) and Whitehead (1970), using a constant bendwidth wave analyzer, obtained $3 \mathrm{~Hz}$ bandwith frequency-by-arnplitude acoustic spectra of vowels produced by adult males, both normally and with simulated vocal roughness. They found that for all vowel productions, spectral noise was most prominent in the lower spectral frequencies and tended to decrease in the higher frequencies. Similar results were obtained by Iively and Emanuel (1970) who studied the spectral noise levels associated with normal and simulated rough vowel productions of adult females, and by Hanson (1970) who studied the phonations of adult male subjects with pathologically rough voices. The results of these investigations tend to support the data repoxted by Isshiki, Yanagihara and Morimoto (1966) and Yaragihara (1966a, 19663). 
A further comparison between the studies by Sansone and Emanuel (1970), Iively and Emanuel (1970), Whitehead (1970), and Hanson (1970) reveals that vowel roughness exists in the normal voice, but to a lesser degree than in either simulated vowel roughness or vowels produced by pathologically rough voices. Sansone and Emanuel obtained median roughness ratjngs for vowels produced by males first normally and then with simulated roughness. Based on a five point equal-appearing-interval scale the median roughness ratings ranged from 1.19 to 1.69 and 3.58 to 4.26 respectively. Whitehead obtained median roughness ratings, using the same roughness scale fox vowel.s produced normally, with rocel fry and with simulated roughness by auit maies. His obtained median roughness ratings ranged from 1.56 to $2.11,4.48$ to 4.76 and 4.08 to 4.39 respectively. Hanson's obtained median roughness ratings for vowels and connected speech samples produced by pathological male voices ranged from 2.50 to 3.53. Iively and Emanuel obtajned median roughress ratings of 1.14 to 1.55 and 3.60 to 4.08 for normal and simulated rough vowels respectively, produced by females. In each of these studies the simulated and pathologically rougin vowel producitons consistently received higher median roughness ratings than their normal counterparts. When a comparison is made between the overall median roughness ratings reported for the normal nale speakers by Sansone and Emanusl (1970) and Whitehead (1970) 
to those reported by Lively and. Emanuel (1970) for the normal female speaker it is apparent that the vowels produced by the male speakers were rated more severely than the vowels produced by the female speakers. Lively and Emanuel (1970) report that a direct comparison, based on sex difference, can not be made between their study and that of Sansone and Enanliel (1970) because the roughness ratings assigned to rormal productions may have been influenced by the degree of simulated roughness for the vowels in each study. She suggests that the roughness associated with normal rowels may be different for the two sexes because of rocal pitch differences between the ะละอะ.

It is generally agreed that sex associated fundamental frequency difierences are due primarily to differences in the length and mass of the rocal folds (Hollien, 1960; 1962: Wurpiy, 1964; Fisher, 1966; Green, 1966; Brodnitz, 1968; Moore, 1971; Boone, 1971). The males rocal folds average $18 \mathrm{~mm}$ in lengtin while the fewales average $10 \mathrm{~mm}$ in length. The average fundamental frequency for the female is apprcyimately 200 cps while that for the male is approximately 125 cps (Fisher, 1966; Brodnitz, 1968; Boore, 1971). Sex related pitch differences appear to be an accepted fact. The effect of these pitch differences on the perception of quality disorders is not cleax, however. As stated earlier, Iively ard Emanuel (1970) point out that perception of 
roughness for vowels proauced normally by females may be different than those produced normally by males because of pitch differences. It will be recalled that wendahl (1963) in his laryngeal analog stuày reported slight frequency variations (as small as plus or minus one $\mathrm{Hz}$ ) were perceived as rough and that frequency variations around a median frequency of $100 \mathrm{~Hz}$ was rated by the judges in his study as being more rough than the same frequency variations around a median frequency of $200 \mathrm{~Hz}$. The inferences made by Ijvely and Emanuel, and Wendahl not only points out the importance of considering the speakex's pitch level when assessing vocal roughness but also that it might be benefiaial to the vojce clinician to regard males and females as two separate populations when assessing the sererity of vocal quality disorders. It has been the purpose of this chapter to review the literature on vocal roughness and to provide background information for the present investigation. 
OHAPTIR III

METHODS AND PROCEDURES

It has been hypothesized by Wondahl (1963) that if a male and a female with equal apexiodictity in theix voices were judged for vocal roughness, the male would be judged as being the rougher due to his lowen pitch levej. Werdahl based this hypothesis or the result, of his study in which he employed synthesized vowel stimuli and not on human voices. It was the purpose of the present study to investigate the effects of Spearex-sex-ijfference (SSD) on listeners perception of vocal roughness in normel. male and femele productions of the vowel [a].

\section{RESEARCH QUESTION}

The following research question was invastigated regarding the effect of SSD on listezers' perceptual judgements of vocal roughness:

When male and female productions of the rowel [æ1, having previous]y received the same roughness rating, are paired and presented to judges, will the male vowel production be selected as the more vocally rough?

Subjects. The subjects in this study included 150 adults, 75 femaies ari 75 males. Suijects were all students at Portland State Uuigersity, Fortland, Oregon, majoring in 
a variety of fields. Criteria for subjest selection were (1) that subjects be between 18 and 45 years of age and (2) have no present or past history of rojce, speech or language disorders. Subjects were asked if trey were currently or had in the past been to an otolaryngologist due to a voice problem or received voice, speech or ianguage therapy from a speech pathologist. The investigator was not concerned whether the subject was a smoker ox suffered with allergies. The primary concern was that subjects had normal sounding voices at the moment and no previous history of a voice disorder.

Each of the 150 subjects produced the isolated rowel [a] for approximately 3 seconâs duration at a corfortable pitch level. When producing this rowel each subject sat before an Unidyne III microphone (Model 545) placed at a 70 degree angle to his mouth and six inches in front of his mouth. Each subject visually monitored the intensity of his phonation within a plus or minus $2 \mathrm{~dB}$ by means of a VU meter of an Arnpex magnetic dual-channel tape recorder (Model AG-500). Prior to subjects actually producing the rowel sample, the experimenter explaired and denonstrated the procedure and allowed the subject several practice trials. All subjects' rowel productions were recorded for later analysis by the Ampex tape recorder. These 150 recorded vowel productions served as the voice samples for this investigation. The voice samples were dubbed onto two 
aditional tapes which were used in the two judging tiasks in this investigation. The two tapes will be referred to as Iistening $\mathrm{Tape} 1$ ( $\mathrm{IT}-1$ ) and Iistening Tape 2 (IT-2). The purpose of these tapes and the metnods used in preparing them are as follows:

\section{Listening Tape 1. IT-1 contained a.l 150 rowel} productions. Female subjects' productions of [a] made up the first 75 samples on the tape; male subjects' productions of [æ] made up the second. 75 vowel samples on the same tape. IT-1 was played for thrse experienced speech pathologists each of whom made vocal roughness ratings for each of the 150 vowel produntions. Ratings of vocal roughness were made on a five point equal-appearing-interval scale with number one being designated as the least rough and number five being designated as the most rovgh. Because the rating of vocal roughness for normal speakers has proven to be a difficult perceptual task (Sansone and Emanuel, 1970; Iively and Emanuel, 1970; Whitehead, 1970) judges were given practice in rating both male and female vowel samples before actually beginning the rating task. During the practice session and the actual rating task judges were permitted to hear each vowel sample as many times as they wished and to mutually discuss theix ratings of the various vowels if they felt it necessary. The practice session took twenty minutes. The rating task took one 
houx. All vowel roughness ratings were made in a quiet room with the judges seatied in front of an Ampex speaker (Model AG-500) through which the vowel stimuli were played. The judges were given the opportunity for a rest period at fifteen minute intervals.

Following the rating of the 150 vowel samples, a second listening tape was prepared which contained the voice samples employed for the second judging task. The purpose and method of preparing Im-2 was as follows:

Listening Tape 2. I'l-2 contained 100 selected vowel samples (50 female and 50 male) and was constructed in the following fashion:

1. Those vowel samples on which judges had agreed in their ratings withir one scale value in IT-1 were assigned single number ratings. For example, jf a particular vowel had received ratings of 4,3 and 4 respectively, by the three judges, the assigned rating was 4. If a vowel received. respective ratings of 3,4 and 3 the assigned rating was 3 .

2. Male and female vowel productions having the same assigned roughness rating, were then arranged in pairs to form 50 pairings each containing an [æ] produced by a male speaker and an [æ] produced by a female sneaker. For example, a vowel assigned 
a roughness rating of 1 from a female speaker was paired with a vowel assigned a rating of 1 from a male speaker. This procedure continued until ten vowel pairings for each of the five roughness rating levels had been construcied. Male and female vowel samples for each of the ten pairs at each of the five roughness rating levels were selected in a random fashion. When a vowel sample was drawn from the pool it was returned to the pool to insure that each sample had the opporitunity of being selected an equal number of times. At four of the roughness rating levels (levels 1 and 5 for fenales and levels 2 and 5 for males) fewer vowel samples went into the pool. The reason for this was that judges on the original rating task did not agree in their vocal roughness ratings (within one scale value) an equal number of times at ali rating levels.

3. The 50 vowel pairings were made by dubbing the selected vowels from the original data tape onto IT-2. Precautions were taken to insure that male anc semale vowel productions of a particular pair had an equal chanoe of being first or second in a pair. Each of the vowel paixings were separated by approximately a one second interval. The 
order of presentation of the 50 pairings was determined randomly, without regard to vocal roughness rating Jevels (See Appendix B).

4. Ten of the 50 vowe 1 pairings were randonly selected and placed aftex the 50 original pairs at the end of IT-2. These ten pajrings were utilized to assess judges' reliability for the perceptual judging task described in the following section.

5. Ten speech pathologists listened to the 50 male-female vowel pairs of IT-2. Five speech pathologists heard IT-2 on one occasion with the five aúditional speech pathologists hearing. LT-2 some two weeks later. Both judging sessions took place in the same room with the five listeners seated in a semi-circular fashion in front of an Ampex loud speaker (Nodel AG-500) through which the vowel pairs were presented. The judging task for the ten speech pathologists involved making a forced-choice response in which they selected the rowel sample in each of the 50 pairs, they perceived as being the more vocally rough of the two. Specific instructions given to the ten judges were as follows:

Ycu will hear two speakers produce the same vowel. After the second speaker has finished, circle the number 1 or 2 according 
to the epeaket whose voice you perceive as being the most vocally rough. Do the same for the other pairs of vowel productions. Do not leave any space blank-guess if you have to--but circle only one nuriber for each space.

The vowel productions may vary according to parameters othex than roughness; however: you are asked to ignore these variations. As you are asked to determine which production you perceive to be the most vocally rough, there are no right or wrong decisions. Therefore, make your decision independent of the person sitting next to you. Do not discuss youx decjsions during the judging session. You may hear each pair as many times as you wish. Are there any questions?

Prior to beginning the actual judging task the ten judges were given practice in making forcedcnojce juagentris. Ten paits of vowel samples not used in the actual judging task, were played for the judges. Judges made forced-choice Iesponses to these vowel pair samples and then mutually discussed their rationale for selecting one vowel of a pair as being rougher than the - other. During the actual judging task judges were allowed to hear each vowel pair as often as they wished but were not permitted to discuss their choices for the 50 experimental or the 10 reliability vowel pairs. The instmaction and training pexiod took 30 minutes. The judging task took 45 minutes. 
CIIAPTIER IV

RESULIRS AND DISCUSSION

\section{RESULPS}

The purpose of this investigation was to detemine the effects of Speakex-SEX-Difference (SSD) on listeners: perception of vocal roughness in nomally produced vowels. on the basis of previous investigations by Wendahl (1963) and others (Sancone ard Emanuei, 1970; Iively ard Emanuel, 1970: Whitehead, 1970) it has been suggested that when hearing two productions of the same vowel, which had received approximately equal scale value ratings for rouglness severity, listeners would tend to perceive the lower pitched voice (male) as being more vocally rough than the higher pitched roice (female). To test tilis hypothesis an initial step in this study, previously disw cussed in Chapter IIX, involved the rating by three judges of 150 productions of the vowel [as] (75 female and 75 inale) on a five point equal-appearing interval scale. Table I gives the roughness ratings assigned by the three judges to each of the 150 rowel samples.

Table II shows the degree of agreement reached by the three judges for samples where they agreed 100 percent 
THSTE I

THREE JUDGES ROUGONISS RATIYGS ON A FIVE POINT SOATE FOR DACH NAIT AND

FEMAIE/YOWEI PRODUCTION

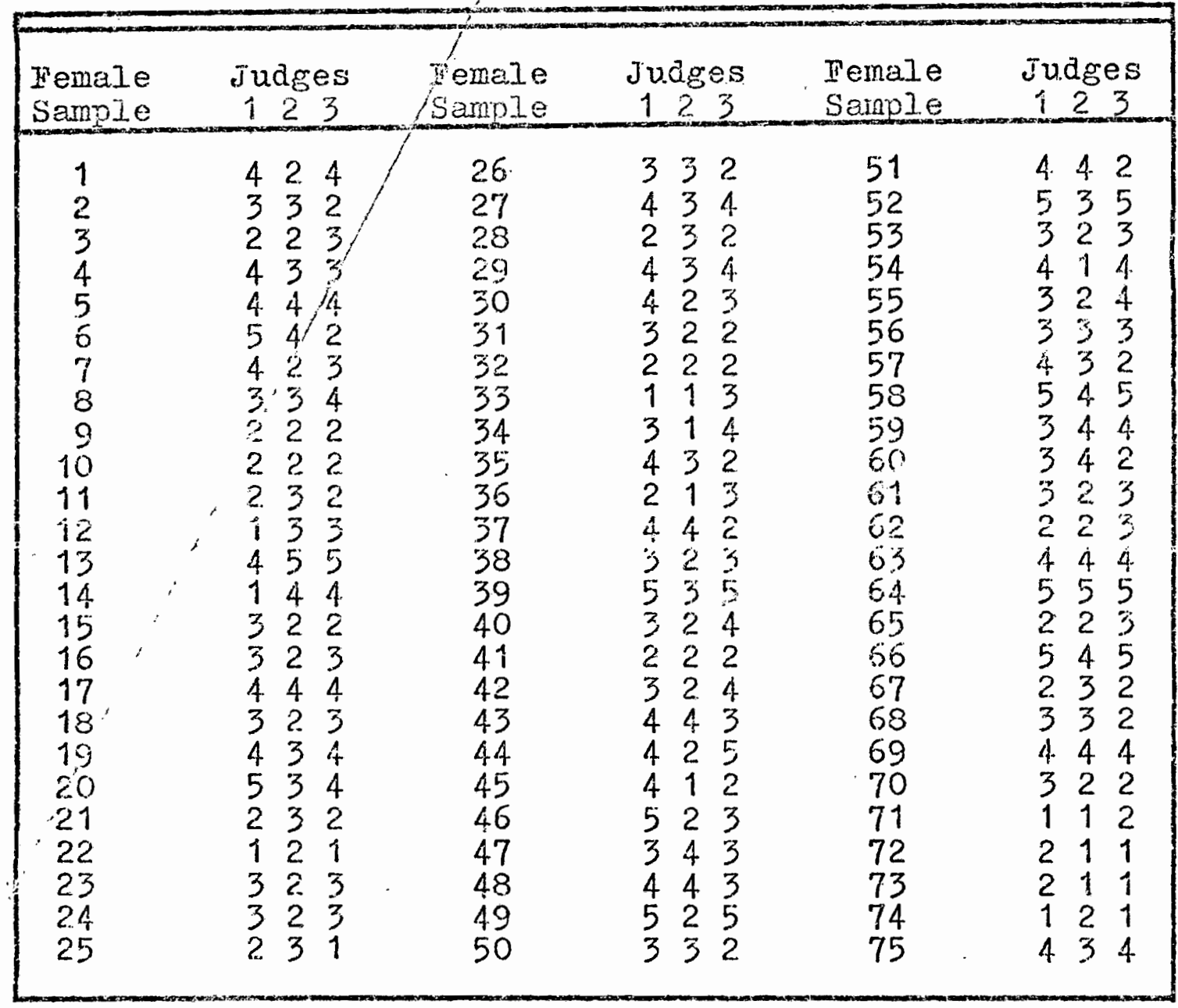


TABIE $x-\infty$ ontinued

\begin{tabular}{|c|c|c|c|c|c|}
\hline $\begin{array}{c}\text { Male } \\
\text { Sample } \\
\end{array}$ & $\begin{array}{c}\text { Judiges } \\
123 \\
\end{array}$ & $\begin{array}{c}\text { Male } \\
\text { Sample }\end{array}$ & $\begin{array}{r}\text { Judges } \\
123 \\
\end{array}$ & $\begin{array}{c}\text { Male } \\
\text { Sample } \\
\end{array}$ & $\begin{array}{c}\text { Juages } \\
123\end{array}$ \\
\hline $\begin{array}{l}1 \\
2 \\
3 \\
4 \\
5 \\
6 \\
7 \\
8 \\
9 \\
10 \\
11 \\
12 \\
13 \\
14 \\
15 \\
16 \\
17 \\
18 \\
19 \\
20 \\
21 \\
22 \\
23 \\
24 \\
25\end{array}$ & $\begin{array}{lll}3 & 3 & 1 \\
3 & 2 & 2 \\
3 & 3 & 2 \\
1 & 2 & 1 \\
3 & 3 & 2 \\
4 & 4 & 3 \\
4 & 1 & 4 \\
4 & 3 & 2 \\
2 & 1 & 2 \\
5 & 4 & 4 \\
3 & 1 & 4 \\
3 & 5 & 3 \\
4 & 3 & 4 \\
4 & 3 & 3 \\
4 & 4 & 3 \\
3 & 4 & 2 \\
4 & 4 & 3 \\
4 & 4 & 3 \\
1 & 1 & 1 \\
4 & 5 & 4 \\
3 & 5 & 3 \\
5 & 5 & 5 \\
5 & 5 & 5 \\
2 & 3 & 2 \\
2 & 4 & 2\end{array}$ & $\begin{array}{l}26 \\
27 \\
28 \\
29 \\
30 \\
31 \\
32 \\
33 \\
34 \\
35 \\
36 \\
37 \\
38 \\
39 \\
40 \\
41 \\
42 \\
43 \\
44 \\
45 \\
46 \\
47 \\
48 \\
49 \\
50\end{array}$ & $\begin{array}{lll}3 & 3 & 5 \\
2 & 2 & 2 \\
4 & 4 & 3 \\
5 & 5 & 4 \\
4 & 3 & 3 \\
3 & 4 & 2 \\
5 & 4 & 5 \\
2 & 1 & 1 \\
4 & 3 & 4 \\
1 & 1 & 2 \\
3 & 2 & 2 \\
4 & 3 & 4 \\
3 & 3 & 2 \\
2 & 1 & 3 \\
4 & 3 & 4 \\
3 & 5 & 3 \\
2 & 3 & 3 \\
1 & 1 & 1 \\
2 & 2 & 2 \\
1 & 2 & 1 \\
3 & 3 & 2 \\
4 & 4 & 2 \\
1 & 2 & 1 \\
5 & 3 & 5 \\
2 & 2 & 2\end{array}$ & $\begin{array}{l}51 \\
52 \\
53 \\
54 \\
55 \\
56 \\
57 \\
58 \\
59 \\
60 \\
61 \\
62 \\
63 \\
64 \\
65 \\
66 \\
67 \\
68 \\
69 \\
70 \\
71 \\
72 \\
73 \\
74 \\
75\end{array}$ & $\begin{array}{lll}2 & 3 & 4 \\
3 & 2 & 2 \\
4 & 2 & 2 \\
1 & 1 & 1 \\
2 & 1 & 2 \\
4 & 2 & 3 \\
3 & 3 & 2 \\
3 & 3 & 3 \\
1 & 3 & 1 \\
4 & 4 & 4 \\
3 & 1 & 4 \\
3 & 3 & 2 \\
4 & 2 & 5 \\
2 & 2 & 2 \\
3 & 3 & 2 \\
2 & 1 & 1 \\
1 & 1 & 2 \\
3 & 1 & 2 \\
4 & 3 & 1 \\
2 & 1 & 3 \\
2 & 2 & 2 \\
4 & 3 & 2 \\
2 & 1 & 3 \\
5 & 2 & 4 \\
3 & 1 & 1\end{array}$ \\
\hline
\end{tabular}




\section{TABII II}

\section{DEGREE OF AGREEMENT BI THREE JUDGES ON ROUGENESS} RATINGS OF SEVENTY-FIVT MALE AND SEVENTYIIVE FEMALE RRODUCTIONS OF THE VOWEI [æ]

\begin{tabular}{|c|c|c|c|c|c|c|c|}
\hline & \multicolumn{2}{|c|}{ Total Asreement } & \multicolumn{5}{|c|}{ Agreement within scale values of } \\
\hline & $\mathrm{IN}$ & 9 & $N$ & II & $\%$ & IN & \% \\
\hline Males & 11 & 14.80 & 49.33 & 21 & 28.00 & 6 & 8.00 \\
\hline Females & 10 & 13.33 & 52.00 & 98 & 24.00 & 8 & 14.60 \\
\hline Total & 21 & 14.00 & 50.66 & 39 & 26.00 & 14 & 9.30 \\
\hline
\end{tabular}

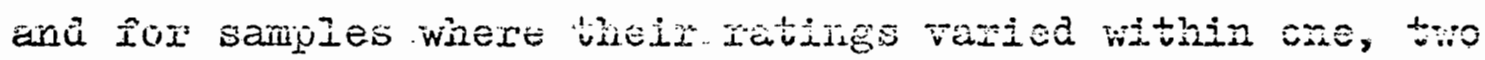
or three scale values. The judges agreed unanimously on 14.80 percent of the male vowel samples, on 13.33 percent of the female vowel samples and there was 14.00 percent agreement on all vowel productions. Percentages of judges rating agreement for the 150 productions, which varied within one, two arid three scale values were 50.66, 26.00 and 9.30 percent respectively.

Those vowel samples upon which the three juages demonstrated 100 percent concurrence or agreement within one scale value were used to fom 50 vowel pairs. Each pair contained one male and ore female vowel production that had received the same roughness rating. A group of ten speech pathologists (five males and five females) 
listened to each of the 50 vowel pairs and made a forcedchoice selection as to which vowel within each pair they percejved to be the most vocally rough. The ten judges' selections of the most rocally rough rowel (maie or female) for the 50 vowel pairs are summarized in Table III. Out of the 500 forced choices made, the judges selected the male vowel samples as being more vocally rough a significantly greater proportion of the time $\left(x^{2}=33.84 ; d f=1 ; p<.001\right)$.

\section{TABLF, III}

TEIN JUDGES : SETECTION RY SEX OF THE MOSI VOCAIIY ROUGH VOWELS OF FIFTY VOWEL PAIRS

\begin{tabular}{|c|c|c|c|c|c|c|c|c|c|c|c|}
\hline Judges & \#1 & $\# 2$ & it3 & 莎4 & 拉5 & \#6 & $\# 7$ & \#8 & $\$ 9$ & $\# 10$ & Total \\
\hline Males & 40 & 40 & 34 & 31 & 26 & 26 & 28 & 23 & 27 & 21 & 296 \\
\hline Females & 10 & 10 & 16 & 19 & 24 & 24 & 22 & 27 & 23 & 29 & 204 \\
\hline & & & & & & & & & \multicolumn{2}{|c|}{ Total } & 500 \\
\hline \multicolumn{12}{|c|}{$296 / 500=0.590$} \\
\hline
\end{tabular}

The ten judges selections of the most vocally rough production (nale or female) at each of the five roughness rating levels are itemized in Table IV. The male vowel samples were selected as beirg more vocally rough a significantly greater proportion of the time at rating levels one $\left(X^{2}=46.08 ; d f=1 ; p<.001\right)$, three $\left(X^{2}=8.00 ; d f=1 ; p<.01\right)$ and five $\left(X^{2}=6.48 ; d f=1 ; p<.02\right)$. At levels two and four 
TABIE IV

TEN JUDGES SELECTIONS EY SEX OF THE MOST VOCAIIYY ROUGH VOWELS OF TEN VOWET PAIRS AT EACH OF THE FIVE ROUGHNESS RATING LEVELS

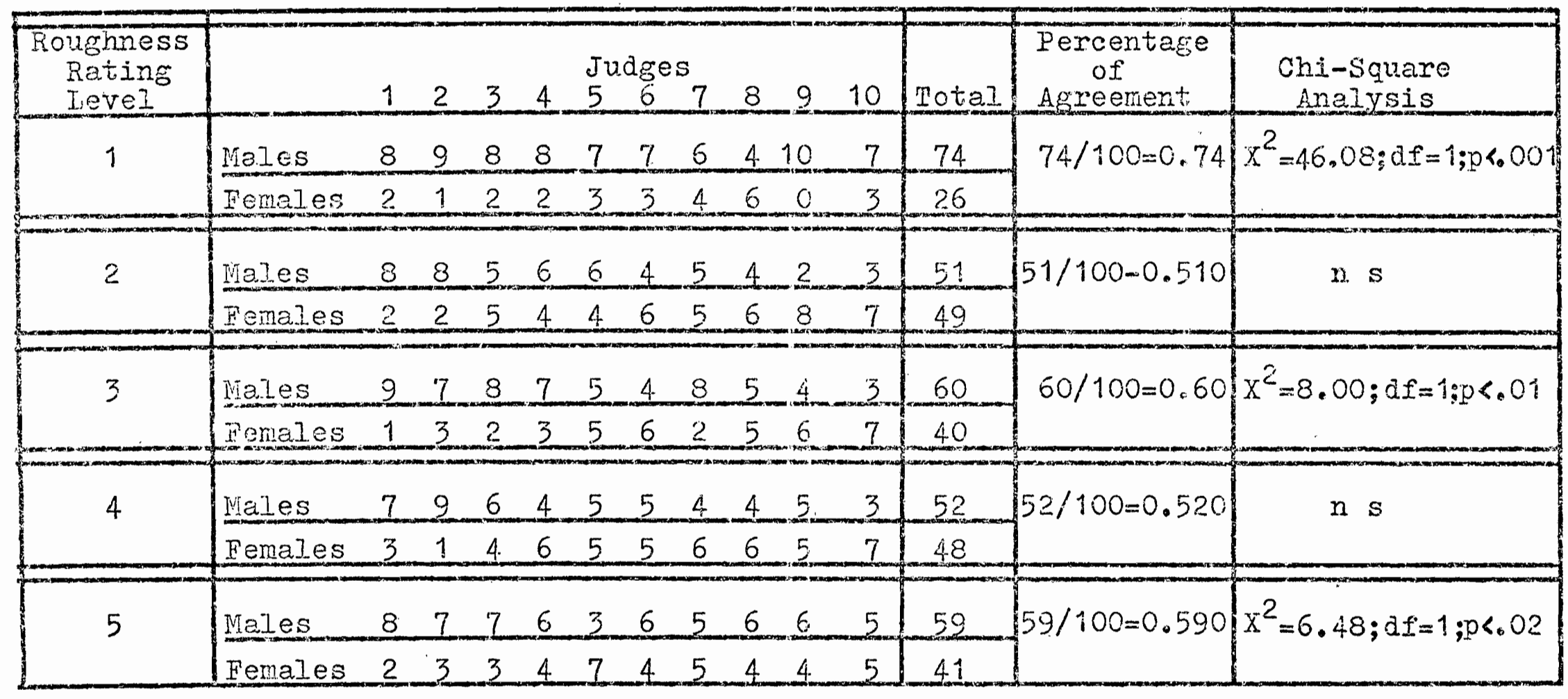


judges showed virtually no preference for selection of the male or female vowels as being more vocally rough ano the Chi-square values were not statistically significant. Separate analyses were also conducted of the vocal roughness selections fox the five male and five female judges in this study. Selections of the most rocally rough vowel (male or female) made by riale judges and by female judges for all 50 vowel pairs are summarized in Table $V$. Out of the 250 forced-choice responses made, the

\section{TABIS $V$}

FIVP MALE AND FIVE FEMALE JUDGES' SELECIIONS BY SEX OF THE MOST VOCALLY ROUGH VOWEL PRODUCTION

\begin{tabular}{|c|c|c|c|c|c|}
\hline \multirow{2}{*}{$\begin{array}{l}\text { Male } \\
\text { Judges }\end{array}$} & \multicolumn{2}{|c|}{$\begin{array}{c}\text { Judges } \\
\text { selections }\end{array}$} & \multirow{2}{*}{$\begin{array}{l}\text { Female } \\
\text { Juäges }\end{array}$} & \multicolumn{2}{|c|}{$\begin{array}{c}\text { Judges' } \\
\text { Selections }\end{array}$} \\
\hline & Males & Females & & Males & Females \\
\hline$\# 1$ & 40 & 10 & $\# 6$ & 34 & 16 \\
\hline if 2 & 33 & 17 & $\# 7$ & 18 & 32 \\
\hline$\# 3$ & 36 & 14 & $\# 8$ & 24 & 26 \\
\hline$\# 4$ & 31 & 19 & $\# 9$ & 21 & 29 \\
\hline$\# 5$ & 31 & 19 & $\# 10$ & 28 & 22 \\
\hline & i 171 & 79 & To & 1125 & 125 \\
\hline & $\begin{array}{l}250=68 \\
7.52 ; d\end{array}$ & $\begin{array}{l}\text { Jercent } \\
0.001\end{array}$ & $\begin{array}{l}12 \\
\text { r. }\end{array}$ & $250=50$ & percent \\
\hline
\end{tabular}


Iive male judges selected the vowels produced by nales as being more vocally rough a substantially greater proportion (68.50 percent) of the time $\left(x^{2}=17.52 ; d r=1 ; p<.001\right)$. of the 250 forced-choice responses made by the five female judges, male and female produced vowels were chosen with equal frequency and the Chi-Square value was not significant $(125 / 250=50.00$ percent $)$.

Male and female judges' selections of the most vocally rough vowels at each roughness rating level are sumnarized in Table VI. At roughness rating level one, both male and female judges selected male vowel productions as being more vocally rough a significantly greater proportion of the time $\left(X^{2}=20.00 ; 0 \hat{I}=1 ; p<.00 i\right.$ ior nale judess; $x^{2}=12.96 ; a r=1 ; p<001$ for female judges). At roughness rating level two, male judges selected the male produced vowels as being more rocally rough a significantly greater proportion of the time $\left(x^{2}=10.24 ; d f=1 ; p<.01\right)$ while female judges illustrated a statistically significant preference for selection of female produced vowels as being more vocally rough $\left(x^{2}=7.84 ; \bar{d} f=1 ; p<.01\right)$. At roughness rating levels three $\left(x^{2}=19.36 ; d f=1 ; p<.001\right)$, four $\left(x^{2}=5.76 ; d f=1 ; p<.02\right)$ and five $\left(x^{2}=5.76 ; d f=1 ; p<.02\right)$ nale judges selected male vowel samples as being more vocally rough a significantiy greater proportion of the time. At these same roughness rating levels, however, female juajges showed no significant preference for selection of the male or female produced vowels as being 


\section{TABIE VI}

FIVE MAIE AND FIVE FEMALE JUDGES' SELECTIONS BY SEX OF

THE MOST VOCALIY ROUGH VOWEL PRODUCMION AT EACH

OF FIVE ROUGHNESS RATING IEVEIS

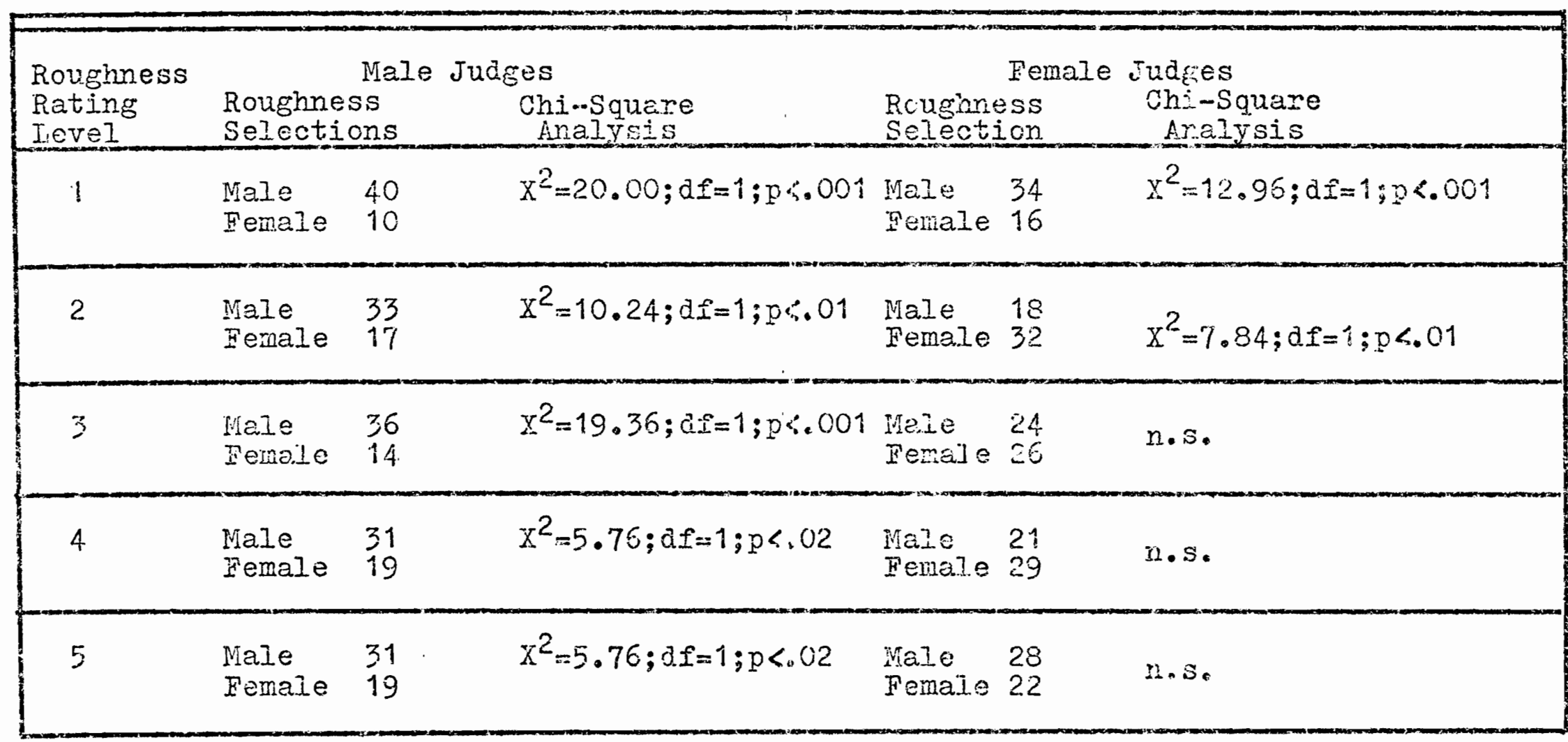


more vocally rough and Chi-Square values were not significant.

Intra-Judge Reliability. To assess judges' reliability for the second listening task (II-2), ten vowel pairs were selected randomly from the fifty vowel pairs of IT-2 and placed at the end of IT-2. Intra-judge reliabilj.ty was then computed by comparing each judges' selections of the most vocally rough vowel of the ten repeat pairs with his responses to those same pairs in IT-2. Intra-judge reliability ranged from 40 percent to 90 percent for the ten judges with a mean agreement of 73.00 percent. Intrajudge reliability for male judges ranged from 70 percent to 90 percent with a mean agceement of 80.00 percent. Intra.judge reliability for female judges ranged from 40 pexcent to 90 percent with a mean agreement of 66.00 percent. Table VII shows the percertages of intra-judge reliability.

TABLE VII

INTRA-JUDGE RELIABIIITY

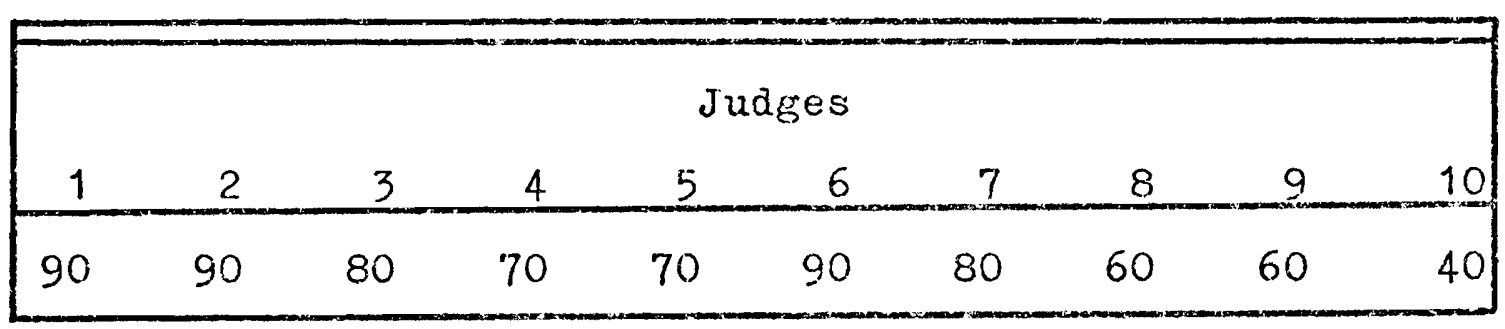

Inter-judge Agreement. Inter-judge agreement for the ten jucges ranged from 32 percent to 74 percent with 
a mean agreement of 56.33 percent. Table VIII shows the pexcentage of intez-juge agreement for the 50 pairs of vowel samples.

\section{TABIE VIII}

PERCENTAGE OT INTER-JUDGE AGREEMENT FOR FIFIYY PAIRS OF VOWEL SAMPLES

\begin{tabular}{|ccccccccccc|}
\hline \multicolumn{10}{|c|}{ Judges } \\
\hline Judges & 10 & 9 & 8 & 7 & 6 & 5 & 4 & 3 & 2 \\
\hline 1 & 54 & 46 & 50 & 60 & 62 & 60 & 74 & 64 & 72 \\
2 & 52 & 58 & 54 & 52 & 58 & 68 & 70 & 64 & \\
3 & 42 & 50 & 42 & 48 & 52 & 58 & 62 & & \\
4 & 56 & 56 & 46 & 58 & 58 & 66 & $\ldots$ & &. \\
5 & 46 & 50 & 32 & 48 & 52 & & & & \\
6 & 58 & 54 & 66 & 52 & & & & & \\
7 & 44 & 54 & 54 & & & & & & \\
8 & 62 & 48 & & & & & & \\
9 & 56 & & & & & & & \\
\hline
\end{tabular}

Inter-judge agreement pereentages were also calculated at each of the five roughness levels. Tables IX, X, XI, XII and XIII show the percentages of inter-judge agreement at each of the five roughness rating levels. At rating level one (Table IX) judges' percentages of agreement ranged from 40 percent to 90 percent, with a mean agreement of 62.66 percent. At rating level two (Taole $X$ ) judges: percentages 


\section{TABIE IX}

PERCENTAGE OP INTER-JUJGE AGREEMENT BY TEN JUDGES AT ROUGHNESS RATING

IEVEI ONE

\begin{tabular}{|ccccccccccc|}
\hline Judges & 10 & 9 & 8 & 7 & 6 & 5 & 4 & 3 & 2 \\
\hline 1 & 70 & 80 & 40 & 40 & 70 & 70 & 60 & 70 & 70 \\
2 & 90 & 90 & 50 & 70 & 70 & 60 & 70 & 70 & \\
3 & 70 & 80 & 40 & 40 & 70 & 90 & 60 & & \\
4 & 70 & 80 & 40 & 40 & 50 & 50 & & & \\
5 & 60 & 70 & 40 & 50 & 60 & & & & \\
6 & 80 & 70 & 60 & 50 & & & & & \\
7 & 40 & 60 & 60 & & & & & & \\
8 & 40 & 40 & & & & & & & \\
9 & 70 & & & & & & & \\
\hline
\end{tabular}

TABTE $X$

PERCENTAGE OF INTER-JUDGE AGPEEMENT BY TEN JUDGES AT ROUGHNESS RATING LETEL TWO

\begin{tabular}{|ccccccccccc|}
\hline \multicolumn{10}{|c|}{ Judges } \\
\hline Judges. & 10 & 9 & 8 & 7 & 6 & 5 & 4 & 3 & 2 \\
\hline 1 & 50 & 20 & 60 & 50 & 60 & 50 & 80 & 70 & 80 \\
2 & 30 & 20 & 60 & 70 & 60 & 90 & 80 & 70 & \\
3 & 60 & 30 & 70 & 40 & 70 & 40 & 70 & & \\
4 & 50 & 40 & 60 & 70 & 60 & 60 & & \\
5 & 10 & 40 & 40 & 70 & 60 & & & & \\
6 & 50 & 40 & 80 & 50 & & & & & \\
7 & 40 & 50 & 50 & & & & & \\
8 & 70 & 40 & & &. & & & \\
9 & 50 & & & & & & & \\
\hline
\end{tabular}


TABIE XI

PERCENTAGE OF INTER-JUDGE AGREENENT BY TEN JUDGTS AI ROUGHNESS RAIING

LEVEI THRET

\begin{tabular}{|c|c|c|c|c|c|c|c|c|c|}
\hline \multicolumn{10}{|c|}{$J u d g \in S$} \\
\hline Judres & 10 & 9 & 8 & 7 & 6 & 5 & 4 & 3 & 2 \\
\hline 1 & 40 & 50 & 60 & 70 & 50 & 60 & 30 & 70 & 80 \\
\hline 2 & 60 & 70 & 60 & 50 & 50 & 80 & 80 & 50 & \\
\hline 3 & 10 & 40 & 50 & 80 & 40 & 30 & 50 & & \\
\hline 4 & 40 & 50 & 50 & 50 & 70 & 80 & & & \\
\hline 5 & 60 & 50 & 40 & 30 & 70 & & & & \\
\hline 6 & 50 & 40 & 40 & 60 & & & & & \\
\hline 7 & 30 & 40 & 50 & & & & & & \\
\hline 8 & 60 & 50 & & & & & & & \\
\hline 9 & 70 & & & & & & & & \\
\hline
\end{tabular}

TEBLE XII

PERCENTAGE OF INTER-JUDGE AGREEMENT BY

TEN JUDGES AT ROUGHNTSS RATING

LEVEL FOUR

\begin{tabular}{|ccccccccccc|}
\hline \multicolumn{10}{|c|}{ Judges } \\
\hline Judges & 10 & 9 & 8 & 7 & 6 & 5 & 4 & 3 & 2 \\
\hline 1 & 40 & 40 & 30 & 70 & 70 & 60 & 70 & 40 & 60 \\
2 & 40 & 60 & 50 & 30 & 40 & 60 & 50 & 70 & \\
3 & 30 & 50 & 20 & 40 & 30 & 70 & 60 & & \\
4 & 50 & 70 & 40 & 80 & 50 & 70 & & \\
5 & 40 & 60 & 30 & 50 & 40 & & & \\
6 & 60 & 60 & 70 & 70 & & & & \\
7 & 50 & 70 & 40 & & & & & \\
8 & 90 & 50 & & & & & & \\
9 & 40 & & & & & & & \\
\hline
\end{tabular}


TABI, XIII

PERCENTAGE OT INTER-,JUDGE LGREENENT: BY TEN JUDG ASS ROUGHNESS RATING

LEVEL FIVE

\begin{tabular}{|cccccccccc|}
\hline \multicolumn{10}{|c|}{ Judges } \\
\hline Judges & 10 & 9 & 8 & 7 & 6 & 5 & 4 & 3 & 2 \\
\hline 1 & 70 & 40 & 60 & 70 & 50 & 50 & 80 & 70 & 70 \\
2 & 40 & 50 & 50 & 40 & 70 & 50 & 70 & 60 & \\
3 & 40 & 50 & 30 & 40 & 50 & 60 & 70 & \\
4 & 70 & 40 & 40 & 50 & 60 & 70 & & \\
5 & 60 & 30 & 40 & 40 & 30 & & & \\
6 & 50 & 60 & 50 & 40 & & & & \\
7 & 60 & 50 & 70 & & & & & & \\
8 & 50 & 60 & & & & & & \\
9 & 50 & & & & & & & \\
\hline
\end{tabular}

of agreement ranged from 10 perceni to 90 percent, with a mean agreement of 54.88 percent. Judges' agreement at rating level three ( $T a b l e X I$ ) ranged from 10 percent to 80 percent with a mean agreement o: 54.88 percent. Agreement at rating level four ( 90 percent with a mean agreement of 52.44 percent. Agree-ment at rating level fire (IIable XIII) ranged from 10 percent to 80 percent with a mean agreement of 55.76 percent. 


\section{DISCUSSION}

It has been show that judges, when listening to two synthesized vowels of approximately equal aperiodicity, tend to rate the lower pitched rowel as being more vocally rough (Wendahl, 1963). If this is true for listeners' perception of human vowe productions as well, then it might be advantageous for voice clinicians, when raking vocal roughness assessments, to regard male and female speakers as two separate populations in view of the inherent pjtch differences between the sexes. The findings of this investigation indjcate that when judges select the most rocelly rough rnwel from pairs of male and temaie normal rowel productions (assigned the same roughness rating) they chose the male produced vowels a significantly greater proportion or the time. This result tends to support the finaings of Wendahl's study of Iisteners' perception of rocal roughness in synthesized vowels and the contention that SSD does affect listeners' perception of vocal roughness. This finaing strongly sugeests the value of regarding male and fenale speakers as two separate populations when making vocal roughness assessments.

The phenomenon of vocal roughness may be viewed along a continuum. Normally produced vowels can be expected to be perceived as less rough than simulated rough vowels. Simulated rough rowels will be perceived as being less 
rough than pathological.Iy rough. vovels. The assignment of rocal roughness ratings to normal speakers: vowel productions, however, is a difficult perceptual task. The range of vocal roughness ratings for normal vowel productions of male and female speakers is somewhat more constricted than for simulated rough vowels (Sansone and Emanuel, 1970; Iively and Imanuel, 1970; Whitehead, 1970) and for pathologicaily rough vowels (Hanson, 1970). Judges in the present study made forced-choice selections of the most rocally rough vowel. (male or female) of 50 rowel pajis. Vowels within each pair had been assigned idertical roughress ratings (baseà on a five point soale) by three judges in a prior judging session. There were teri such rowel pairs at each of the five roughness rating ievels. The judges' selections at each of the five roughness levels revealed that the male produced vowels were selected as being more vocally rough a significartly greater proportion of the time ai roughess rating levels one, three and five. The judges illustrated virtually no preference, however, for selections of nale or female vowel samples at roughness levels two and four. lhus, when judges nade forced-choice selections between male and female vowel productions they chose the male produced vowels a significantly greater proportion of the time at low (rating level one), moderate (rating level-tinree) and high (rating level. five) points on the five pojnt equal-appearing rough- 
ness scale. They aisplayed no sejection preterence, however, for intermediate levels (cating levels two and four). Mhis tends to suggest that it might be more advantageous to rate normal vowel productions on a three point scale rather than a five, six, seven or eight point interval scale.

One of the more interesting and somewhat surprising findings was that not only aid the sex of the speaker. affect judges' perception of vccal roughness but that the sex of the judges also appeared to influence the perception of vocal roughness. The five male judges in this study selected male produced vowels as being more vocally rough a significantly greater proportion ox the time for a.l工 50 rowel pairs and at each of the five roughness rating levels. The five female judges, on the other hand, illustrated no sex bias with respect to vocal roughness selections for the total sample. They did show a significant preference for males at roughness level one, a significant preference for females at roughness level two, but'no preference at roughress levels three, Four and five. Moreover, male judges illustrated substantially greatex inter-judge agreement ( $\bar{X}=65.80$ percent) than did the female judges $(\bar{X}=55.00$ percent). This fact coupled with the fact that the mean intra-judge reliability for male judges $(80.00$ percent) was substantially higher than that for female judges ( 66.00 percent) may indicate that the male evaluators 
of vocal roughness may ve more consistent, and perhaps more sex biased, in making assessments of rocal roughness chan female evaluators. One might also speculate that maie listeners tend to equate low-pitched male voices with the quality roughness on a psychological basis. These interpretations mast be riewer cautiously, however.

Intra-judge reliabilicy and intex-judge agreement was substantially lower for the present study than in previous similar intestigatiorss. For example, in the studies of Sansone and Emanuel (1970), Iively and Emenuel (1970) and whitehead (1970) reported intramjudge reliabilicy ranges were from 92 percent to 100 percent. Inter-judge agreement ranges wexe farn 80 pereent to 100 percont: These studies differed nethodologically from the present investigation, however. The judges in the cited studies were asked to rate vocal roughness on a five point scale, rather than to select by means of a forced-choice response, the rougher of two vowels. In addition reliability measures, in the aforementioned studies, were based on percentages of judges agreement within one scale value which affords some margin of disagreement. The forced-choice task imposed upon the ten judges in the present study enhanced the possibility for disagreement.

It is possibje that selection of the rougher of two vowels on a forced-choice basjs is a more difficult pexceptual task and therefore necessitates more judge training 
than when uaking a vocal roughness scale rating. Juage training in this investigation wes much less intense than that employed in previous studics (Sansone and Emanuel, 1970; Lively ana Emanuel, 1970; Whitehead, 1970; Hanson, 1970). It was felt, however, that by providing limited judge training in the forced-choice response task, conditions might more closely parallel what transpires in the clinical situation.

The possibility that the sex of the listener might influence rocal roughness percepticis has yet to be exploreà. Only one investigator (Coleman, 1971) has reported the sex of judges used in perceptual studies of vocal roughness. the fact that the male jugres in the rresent study showed substantially higher intra-judge reliability and interjudge agreement points out the importance in considering and possibly controlling for listener sex in future investigations of this nature. Furthermore, it may be that males and females, when making roughness ratings, react differently to particular components of the human voice. Further research would seem in order to answer this question. 
CHAPIFR V

SUMDARY AND CONCIUSIONS

\section{SUMTIARY}

The purpose of this study was to investigate the effects of speaker-sex-difference on listeners' perception of vocal roughness in the vowel [a] produced by normal male and female speakers. In a previors investigation by Wendahl (1963) it was found that when listening to two synthesized vowels, of equal aperiodicity, judges tended to rate the lower pitched vowel as being more vocally rough. It this is true for listeners' perception of human vowel productions as well then it might be advantageous for voice clinicians, when making rocal roughness assessments, to regard male and female speakers as two separate popula.tions in view of the inherent pitch differences between the sexes.

In this current investigation, pairs of vowels produced by normal adult maile and female speakers were presented to 10 speech patholcgists ( 5 males and 5 females). Each vowel pair contained one mele ard one female production of the vowe]. [æ] which had been assigred equal roughness ratings in a previous judging task. The 50 vowel pairs contained 10 pajrs of vowels at each of five roughness rating levels. 
The 10 judges were required io jisten to each of the 50 pairs and to make a foreed-chojee selection of the most vocally rough production within each pair.

The findings in this study revealed that for the 50 vowel pairs the judges selected the vowels produced by males as being more vocally rough a significantly greater proportion of the time. With respect to the rite roughness rating levels, judges chose the nale prodaced vowels as being rougher a significantly greater proportion of the time at rating levels one, three and five, but, illustrated no significant preference between the sexes at sating levels two and four. Further analysis revealed that the five male judeoe selectod the vowels produced by males as being the rougher a significantly greater proportion of the time for all 50 pairs at each of the five roughness rating levels. The five female judges, on the other hand, i.llustrated no significant preferences between the sexes for the 50 vowel pairs. They did show a significant preference for the males at rating level one, a. signiricant preference for the females at rating level two but no significant preferences at rating levels three, four and five. In addition, male judges illustrated substantially greater inter-judge agreement and intra-judge reliability for this judging task than did the female judges.

The principle firdings of this investigation tend to support the findings of Wendahl's (1963) study of listeners' 
perception of rocal rolighness in symthesized vowels and the contention that spearer-sex-djfference does affect listen-m exs perception of vooul roughness. These fincings also strongly suggest the value of regarding male and female speakers as two separate populations when making vocal. roughness assessments. Further implications indicate that it might be more advantageous to empioy a three point scale rather than a five point scale, when judging normal. male and female rowel productions. There was also a significant male bias displayed by male judges in this study which was not observed in the female judges. What influence the sex of the judge has on the pesception of rocal roughness has Jet to be explored. Male judges in the present study showed substantially righer intra-judge reliability and inter-judge agreement. This points out the importance in considering and possibly controlling listener sex in future investigations of this natire. It may be that males and females, when making roughness ratings, react differentiy to particular components of the human voice. Further research would seem in order: to answer these questions.

\section{DONOLUSIONS}

Future investigations of the effects of speaker-sexdifference, on listeners perception of rocal coughness in vowels produced by nowal male and female speakers, might profit from the following alterations and additions to the 
desigh of the present study: .

1. Since the judges in this investigation displayed significant preierences for selecting the male at roughness rating levels one, three and five, future studies might employ a three point scale rather than a five point scale when assessing vocal roughness in normal vowel productions.

2. The fundamental frequencies of the subjects employed in this irvestigation were not assessed. Future research might profit from i) analysis of subjects' fundamental frequency differences, on a paired comparison basis, to determine the effects of these differences on listeners' peroeption of vocal roughness, ard 2) employ subject whois fundemental frequencies encompass the traditional male and female pitch ranges, including the overlapping frequencies of the sexes.

3. Provide more extensive training for the judging task than was employed in this study.

4. The age range for subjects in this stuay was from 18 to 45 years of age. A more restricted age range of 18 to 30 jears of age might relp to control for the variable of the aging process. 


\section{BTBLIOCRAPHY}

Boone, D.R., The Toice and Yoice Mheraoy. Tnglewood Cliffs, New Jersey: Prentice-Hall Inc. (1971).

Bowler. N.W.. A fundamental freauency analysis of harsh rocal quality. Speech Pionog:, 31, 128-134 (1964).

Coleman, R.F., Some acoustic correlates of hoarseness. Masten's Thesis, Vanderbilt Unitversity (1960).

, Effect of waveform changes upon roughness perception. Folia Phoniatr., 23:314-322 (1971).

Coleman, F. and Wendarl, R., Vocal roughness and stirnulus duration. Speech Monogs., 34, 85-992 (1967).

Cooper, F., Peterson, G. and Fahringer, G., Some sources of characteristic rocoder quality. I. Acous. Soc. 1mer: $29.183(1957)$.

Fairbanks, Gos Voice and Articulation Drillbook (2nd Ed.). New York: Haxper' and Brothers (1960).

Fisher, H.Bo, Improving roice and Articulation. Boston: Houghton Nixilin Company (1966).

Green, M.C.I., The Vojce and Its Disorders (2nd Ed.). Philadelphia: J.B. Lippincott Co. (1964).

Hanson, W., Vowel spectral noise letels and roughness severity ratings for voweis ard sentences produced by aulut males presenting abnormally rough voice. Ph.D. Dissertation, injversity of Oklahoma (1970).

Hollier, H., A study of some laryngeal correlates of vocal. pitch. J. Speech Hearing Res., 3, 52 (1960).

Isshiki, N., Ianagihara, No and Morimoto, M., Approach to the objective diagnosis of hoarseness. Folia Phoniatr., 18, 393-400 (1966).

Iieberman, P., Some acoustic measures of the fundamental periodicity of normal and pathologic larynges. J. Acous. Soc. Amer., 35, 34.4-355 (1963). 
Iively, IM.A., Spectxal noise levels and roughness severity ratings for normal and simulaied rough vowels produced by adult females. Ph.D. Dissertation, University of Oklahomia (1969).

and Emanuel., F.W., Spectral noise levels and roughress severity ratings for nomal and simulated rough vowels produced by adult females. J.Speech Hearing Res : 13,503..517 (1970).

Miche?, T. F : Vocal fry and harsbriess. Ph.D. Dissertation, Univexity of rloxida (1964).

Moore, P., Organic Voice Disorders, Englewood Cliffs, New Tersey: Prentice-Hall Inc. (1971).

, and Thompson, C.I., Comments on the physiology of hoarseness. Arch. Dtolaryio. , 81, 97-102 (1965).

Murphy, A.I., Functional Voice Disorders. Englewood Cliffs, New Jersey: Prextice-HaII Inc. (1964).

Sansone, F.E., Spectral noise levels and roughness severity ratings for normal. and simulated rough vowels produced by ajilt males. Ph.D. Dissertation, Initondity of oklahoma (1969).

, and Emanuel, F.W., Spectral noj.se levels and roughness severity ratings for normal and simulated rough rowels produced by adult males. J.Speech Hearing Res.: 13, 489-502 (1970).

Shipp, T. and Huntington, D., Some accustic and perceptual. factors in acute-laryngitic noarseness. J.Speech Hearing Dis., 30, 350-359 (1965).

Third Regional Workshop on the Rehabilitation Codes and Communicative Disorders. PHS Grant No. B-3676, The National Institute of Neurological Diseases and Blindness, Cominunicative Disorders Research Trainjing Committee $(1967)$.

Timcke, R., von Leden, $H_{0}$ and Moore, l?., Laryngeal vitrations: measurements of the glotic wave, Part 1. The normal vibratory cycle. Axch. otolaryng., 68, $1-19(1958)$.

Wendahl, R., Iaryngeal analog synthesis of harsh voice quality. Folia Froniais., 15, 241-250 (1963).

- Some parameters of auditory roughness. Folia phoniatr. $18,26.32$ (1966). 
- Laryngeal analog synthesis of jitter and shimmer. Folia Pboniats.; 18, 98-108 (1966).

Whitehead, R.I., Some spectrographic and perooptual features of normal, vocal fry, and simulated abnormally rough vowel. phonations. Ph.D. Dissertation, University of okI ahoma (1970).

Yanagihara, No, Hcarseness: investigation of the physiological mechanjsms. Ann. 010. Rhino. Laryno: 76 , $472-488(1967)$.

- Significance of hamonic changes and noise components in hoarseness. J. Speech Fearing Res., $10,531-541$ (1967)。 
APPEIVDIX A

JUDGES 


\section{JUDGES}

Robert W, Bjahely Ph.D.; Processor, Director of Division of Speech Pathology and Araiology, Crippled Child-ren's Division, University of Oregon Medical SchooI, Portiand, Oregori.

Robert H. English D.Tid. ; Professor and Director of Program in Speech ard Hearing Science, Portland State University, Fortland, Oregon.

Warren H. Fay Ph.D.; Associate Professor of Speech Pathology, Crippled Children s Division and Pediatrics, University of Oregon Medical School. Portiand, Oregon.

Mary E. Gordon Mos.; Clinical Supervisor, Portland State University, Portland, Oregon.

Nancy R. Heisley Ph.D.: Volunteer, University of Oregon Medical school: portiand, Oregon.

Joseph H. Hopkins M.S.; Speech Therapist, Parkrose Public Schoojs, Lortiend, Oregon.

Jane P. Iazere Mos.: Private Practice and Consulfant, Erovidence Hospital, Portland, Oregon.

Robert C. Marshall Ph.D.; Chief, eiddiology and Speech Pathology, Veteran's Administration Hospital, PortJand, Oregor.

Norma C. McAleer M.S.; Speech Clinician, Beaverton Schocl District \#48, Beciertion, Oregon.

Marie R. Rau M.S.; Speech Pathologist, Portland Veteran's Administration Fospital, Portland, Oregon.

JoAnn V. Smithpeter M.S.; Speech Pathologist, Private Practice, Portlanä, Oregon.

PauI F. Ventura Ph,D,; Audiologist, Kaiser Foundation Hospital, Selr-mployed Speech and Hearing Clinic, Portiand, Oregor.

Curtis Weiss Th.D.: Assistant Professor of Speech Pathology, University of Oregon lledical. School, Portland, Oregon. 
APPENDT $X$

IT-2 PAIR PRESTNTATION ORDER 


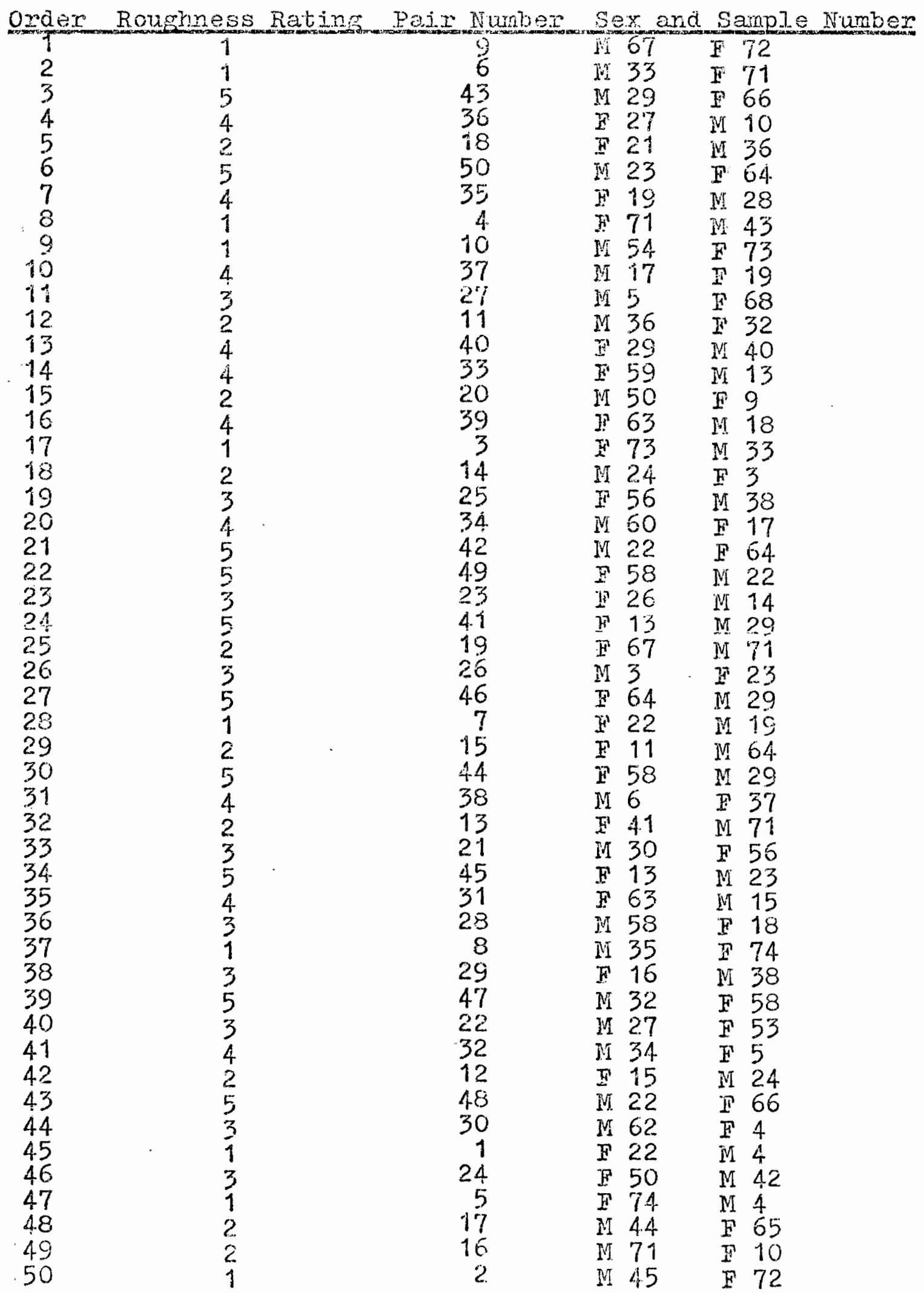

